\title{
A SHORT SYNOPSIS OF Nd: YAG LASER CAPSULOTOMY
}

\author{
V. Sridevi ${ }^{1}$
}

${ }_{1}^{1}$ Associate Professor, Department of Ophthalmology, Rajah Muthiah Medical College \& Hospital, Annamalai Nagar, Chidambaram. ABSTRACT

\section{BACKGROUND}

Posterior capsule opacification (PCO) is a frequently encountered complication of cataract surgery. However, Nd: YAG Laser capsulotomy is accepted as the treatment of PCO. Although Nd: YAG laser capsulotomy is noninvasive, it carries a risk of some complications. The purpose of this article is to have a bird's eye view of Nd: YAG Laser capsulotomy and its effects on the eye.

\section{MATERIALS AND METHODS}

The present study comprised of a total number of 50 patients of Nd: YAG laser in the treatment of posterior capsular opacification after cataract surgery, who attended the Department of Ophthalmology, Rajah Muthiah Medical College and Hospital from 2015 to 2016.

\section{RESULTS}

A total of 50 patients were treated. Out of the 50 eyes that were studied, 25 were Right eyes and 25 were Left eyes. Most of the capsulotomies were done at the level of energy between $1.6 \mathrm{~mJ}$ to $2.4 \mathrm{~mJ}$, consisted of 32 eyes. 10 capsulotomies were done at the level of $1.2 \mathrm{~mJ}$ to $1.5 \mathrm{~mJ}$, while 8 capsulotomies were done at the level of $2.5 \mathrm{~mJ}$ to $3.1 \mathrm{~mJ}$. The minimum amount of energy used was $1.2 \mathrm{~mJ}$ and maximum amount of energy used was $3.1 \mathrm{~mJ}$.

\section{CONCLUSION}

Although this procedure is safe, it is associated with complications like transient intraocular pressure rise, pitting of the intraocular lenses, mild iritis which are not vision threatening and they are transient. Therefore, this treatment modality is cost effective and safe.

\section{KEYWORDS}

Nd: YAG Laser, Posterior Capsule Opacification (PCO).

HOW TO CITE THIS ARTICLE: Sridevi V. A short synopsis of Nd: YAG laser capsulotomy. J. Evolution Med. Dent. Sci. 2017;6(63): 4593-4597, DOI: $10.14260 /$ Jemds/2017/994

\section{BACKGROUND}

The frequently encountered long-term complication after cataract surgery continues to be posterior capsular opacification. ${ }^{1}$ This problem has not yet been conquered though it can be treated by Nd: YAG laser capsulotomy.

No single mechanism has been described so far. Some studies believe that a multicellular secondary membrane results from migration and fibrosis of lens epithelium on the posterior capsule. There can be a single layer of anterior capsule epithelial cells which migrate into posterior capsule forming myofibroblasts. This case series gives a synopsis of treatment of PCO by Nd: YAG laser. ${ }^{2}$

Financial or Other, Competing Interest: None.

Submission 13-07-2017, Peer Review 28-07-2017,

Acceptance 31-07-2017, Published 07-08-2017.

Corresponding Author:

V. Sridevi,

Associate Professor

Department of Ophthalmology,

Rajah Muthiah Medical College \& Hospital,

Annamalai Nagar,

Chidambaram-608002.

E-mail: srithithi@gmail.com

DOI: $10.14260 / \mathrm{jemds} / 2017 / 994$

(c) (i) $(\Theta$

\section{Six Factors to Reduce $\mathrm{PCO}^{3}$}

\begin{tabular}{lll}
\hline $\begin{array}{l}\text { Surgery-Related Factors } \\
\text { ("Capsular" Surgery) }\end{array}$ & \multicolumn{2}{c}{$\begin{array}{c}\text { IOL-Related Factors } \\
\text { ("Ideal" IOL) }\end{array}$} \\
\hline $\begin{array}{l}\text { Hydrodissection- } \\
\text { enhanced cortical } \\
\text { cleanup }\end{array}$ & $\begin{array}{l}\text { Biocompatible IOL to } \\
\text { reduce stimulation of } \\
\text { cellular proliferation }\end{array}$ \\
- In-the-bag fixation & - $\begin{array}{l}\text { Maximal IOL optic- } \\
\text { posterior capsule contact, } \\
\text { - Small CCC with edge } \\
\text { on IOL surface }\end{array}$ & $\begin{array}{l}\text { angulated haptic, } \\
\text { "adhesive" biomaterial to } \\
\text { create a "shrink wrap" }\end{array}$ \\
& IOL optic geometry \\
& square, truncated edge \\
\hline
\end{tabular}

\section{Incidence}

PCO causes decline in visual acuity by blocking the central visual axis. These cells on proliferation may cause effects like striae, folds or displacement of IOL.

It has been found that the incidence of PCO (20\%) is low in patients within 3 years and increases steeply by $38 \%$ after 9 years ${ }^{4}$ and $16 \%$ over 7 years period. ${ }^{5}$

In this present ophthalmic scenario of modern surgical techniques and wide array of IOL designs, PCO and Nd: YAG laser capsulotomy rate is declining to $10 \% .^{6}$ 


\section{IOL Designs}

Acrylic sharp edge IOL has higher incidence of PCO than eyes implanted with silicone IOL. ${ }^{7}$

PMMA IOLs are better than polypropylene haptic IOLs because the former expand the capsular bag to the maximum extent but hydrogel IOLs lead to re-closure of $\mathrm{Nd}$ : YAG capsulotomy opening site. ${ }^{8}$

The best choice to avoid PCO is to have a 360 -square edge design IOL. This type of IOL is very useful even in high risk diabetic patients for lowering the rate of occurrence of PCO. ${ }^{9}$

\section{Energy Levels}

The lasing energy beam should be set at the minimum level possible and the beam should be focused behind the posterior capsule. An energy of $1.8 \mathrm{~mJ}$ is enough to open membranous PCO whereas $3.1 \mathrm{~mJ}$ is needed for fibrous PCO. If there is a combination of these two, an initial shot of $3.1 \mathrm{~mJ}$ is given followed by more energy to open the fibrotic PCO.10

Tetzet al (2000) in his case series has found that higher energy is needed for sulcus fixated IOLs. ${ }^{11}$

The average energy used was $12.7+9.4 \mathrm{~mJ}$ as analysed by Auffarth et al (2000). He also found that the laser energy needed was high with sulcus fixated IOLs.

The mean summated energy given by Khanzada and coworkers (2008) was 48.8 mJ. ${ }^{10}$

It is recommended that the lowest possible single pulse laser energy be used for capsulotomy to minimise complications. ${ }^{11}$

\section{MATERIALS AND METHODS}

The present study comprised of a total of 50 patients of $\mathrm{Nd}$ : YAG laser in the treatment of posterior capsular opacification after cataract surgery, who attended the Department of Ophthalmology, Rajah Muthiah Medical College and Hospital from 2015 to 2016.

\section{SELECTION CRITERIA}

\section{Inclusion Criteria}

All patients with postoperative posterior capsular opacification with vision $<6 / 9$.

\section{Exclusion Criteria}

a) Posterior Capsular Opacification (PCO) associated with corneal scars, irregularities, or oedema that interferes with target visualisation.

b) Posterior Capsular Opacification associated with active intraocular inflammation.

c) Posterior Capsular Opacification associated with cystoid macular oedema or other complications that is likely to reduce visual acuity.

d) An uncooperative patient who is unable to remain still or hold fixation during the procedure, with threat of inadvertent damage to adjacent intraocular structures.

As the prevalence rate of Posterior Capsular Opacification after five years of cataract surgery is $50 \%$, size of the sample works out to be 50 cases. All patients with Posterior Capsule Opacification were subjected to Nd: YAG laser capsulotomy. Their particulars like Name, Age, Sex and Address of all the patients were noted.

\section{Local Examination was done as follows-}

a) Visual acuity - BCVA was noted from Snellen's chart or Landolt's broken ring depending upon cases.

b) Slit-lamp examination-

i) Diffuse examination.

ii) Oblique and slit illumination.

iii) Retro illumination.

On the Slit-lamp, apart from the other features of anterior segment, PC opacity was noted and was graded into 3 groups.

c) Direct Ophthalmoscopy: was done and PCO was graded into 3 groups based on clarity of visualisation of posterior segment.

\section{Grading of PCO}

Equal emphasis was placed on ophthalmoscopic evaluation and Slit-lamp appearance. Although the anatomic presence of PCO can be adequately assessed with the Slit-lamp, the ophthalmoscope helped to assess media clarity, which serves as an indirect indicator of functional impairment.

PCO was graded according to the protocol followed in Madurai Intraocular Lens case series. PCO was graded according to following levels of severity based on slit-lamp and dilated direct ophthalmoscopic evaluation.

Grade 0- No PCO, no evidence of PCO seen before and after pupillary dilatation to a minimum of $6 \mathrm{~mm}$. With a direct ophthalmoscope, a clear view of the optic disc, blood vessels and nerve fibre layer is obtained.

Grade 1- No central PCO is seen. PCO is seen only with pupil dilated to a minimum of $6 \mathrm{~mm}$. With a direct ophthalmoscope, a clear view of optic disc, blood vessels and nerve fibre layer is obtained.

Grade 2 - PCO is present in central visual axis detectable with an undilated pupil. With a direct ophthalmoscope, there is a mild obscuration of fundus detail that optic nerve head is clearly seen, but nerve fibre layer and blood vessels are not clearly seen.

Grade 3- PCO is present in central visual axis, with an undilated pupil. With a direct ophthalmoscope, there is marked obscuration of fundus details that even the margins of optic nerve head are not clearly defined, because of PCO.

\section{Tonometry}

Preoperative baseline intraocular pressure was taken by Schiotz tonometer. It was recorded at least 1 hour before the procedure.

\section{Methods}

All patients with Grade 2 and Grade 3 PCO were subjected to $\mathrm{Nd}$ : YAG laser capsulotomy.

The procedure to be done and complications associated with it were described to all patients and informed written consent was taken.

All eyes were dilated with tropicamide $1 \%$ eye drops 1 hour prior to laser therapy and topical 4\% Xylocaine was instilled to each eye under case series. 1\% Apraclonidine eye drops was installed 1 hour before the procedure to blunt the effect of IOP rise.

All the capsulotomies were done using Zeiss Visulas YAG II ophthalmic YAG laser system. Since Nd: YAG laser beam is an invisible infrared ray (wavelength $1064 \mathrm{~nm}$ ), the red semiconductor laser (wavelength $633 \mathrm{~nm}$ ) is used as aiming 
beam from YAG laser. The laser system was so designed that aiming beam becomes co-axial with YAG laser beam and target for alignment is where the 2 alignment spots converge into 1 spot. (Dual beam focusing system).

\section{Technique}

The principle of this technique is to create a central opening in the opacified posterior capsule followed by focusing of laser pulse beam with low energy using small duration. ${ }^{12}$ (nanoseconds).

The initial treatment for PCO with Nd: YAG laser was done by Aron Rosa and Fankhauser which proved superior to surgical dissections avoiding disastrous complications like vitreous loss and endophthalmitis.

Nd: YAG laser capsulotomy has been very effective but can also be visually threatening like retinal oedema and detachment. 13

This Nd: YAG laser is a neodymium doped YttriumAluminium garnet crystal which works on photodisruption principle.

The photons emitted will be forced to travel back \& forth inside a cavity with polished mirrors. When a photon touches an excited particle, it emits a photon with identical wavelength. The number of active photons increases on amplification. ${ }^{14}$

This laser throws a $50 \mathrm{u}$ diameter beam of 30 picosecond in 40 nanoseconds with infrared wavelength $(1064 \mathrm{~nm})$ with a maximum frequency of 4-5 cycles/second.

This laser energy ionises the posterior capsular tissue producing plasma which is not harmful to the eye. ${ }^{15}$

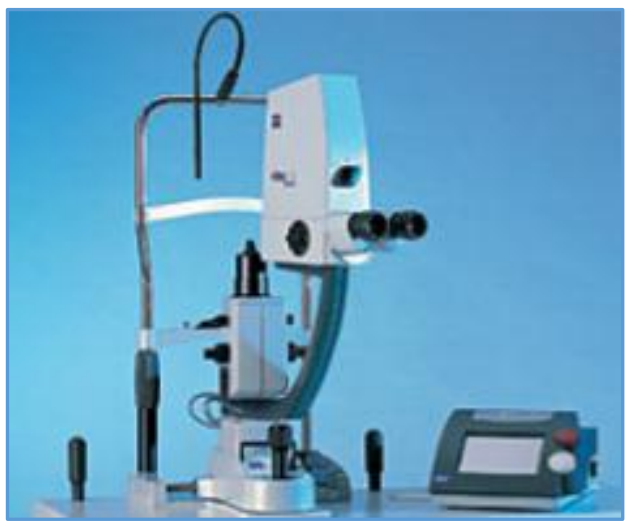

Figure 1. Carl Zeiss YAG Laser

The following followup protocol was used to observe for complications.

\section{Examination was done-}

4 hours after laser.

1 day after laser.

2 weeks after laser.

3 months after laser.

6 months after laser.

\section{Pre-Laser Instructions}

- Complete history \& use of any medication.

- Best corrected visual acuity.

- IOP measurement.

- Slit-lamp examination to find out the type of PCO wrinkles and tension lines in PC.
- Informed consent.

- Pupillary dilatation can be considered for thick PCO \& in uncooperative cases.

- A drop of topical proparacaine hydrochloride has to be instilled before the start of the procedure.

- To focus, the two red spots become one spot to mark the intersection of the He-Ne-beam locating the focal point of lasing beam.

- The procedure is started with less energy $1 \mathrm{~mJ}$ monoburst and successively increased in steps till the tissue breakdown was achieved. If the tissue did not open the focal point was shifted slightly forward.

\section{RESULTS}

A total of 50 patients were studied. The age of patients varied between 42 and 80 years. There were 27 males and 23 females, on whom Nd: YAG laser posterior capsulotomy was done. A comprehensive preoperative ophthalmic evaluation including Snellen's visual acuity, slit-lamp examination, direct ophthalmoscopy, Schiotz tonometry and fundus examination (whenever possible) was done. An inverted U-shaped capsulotomy was done. The postoperative IOP was measured at $4 \mathrm{hrs}$. and $24 \mathrm{hrs}$. after the procedure. The postoperative visual acuity was recorded at $24 \mathrm{hrs}$. after the procedure.

During the course of present case series, the following observations were made:

The age of patients undergoing capsulotomy varied from 42 to 80 years with majority of patients in the age group of 60-70 years.

In our present study of 50 patients with PCO, all eyes were subjected to $\mathrm{Nd}$ : YAG laser posterior capsulotomy.

\begin{tabular}{|c|c|c|}
\hline Sex & No. of Cases & Percentage \\
\hline Males & 27 & 54.0 \\
\hline Females & 23 & 46.0 \\
\hline Total & $\mathbf{5 0}$ & $\mathbf{1 0 0 . 0}$ \\
\hline \multicolumn{2}{|c|}{ Table 1. Gender Distribution of Patients } \\
\hline
\end{tabular}

A total of 50 patients were treated, of which 27 were male and 23 were female as shown in Table 1 . Majority of the people were from a low socioeconomic background.

The youngest age among the female patients was 42 years and oldest was 76 years. Similarly, in male patients, youngest male was of 42 years, and oldest was 80 years. Maximum no. of patients affected were in the age group between 61-70 years. Their number was 22. They constituted more than $40 \%$ of total cases.

\begin{tabular}{|c|c|c|}
\hline Eye & No. of eyes & Percentage \\
\hline Right eye & 25 & 50.0 \\
\hline Left eye & 25 & 50.0 \\
\hline Total & $\mathbf{5 0}$ & $\mathbf{1 0 0 . 0}$ \\
\hline \multicolumn{2}{|c|}{ Table 2. Eye Distribution of Patients } \\
\hline
\end{tabular}

A total of 50 patients were treated. Out of the 50 eyes that were studied, 25 were Right eyes and 25 were Left eyes as shown in Table 2. 


\begin{tabular}{|c|c|c|}
\hline Level of Energy (mJ) & No. of Patients & Percentage \\
\hline $1.2-1.5$ & 10 & 20.0 \\
\hline $1.6-1.8$ & 12 & 24.0 \\
\hline $1.9-2.1$ & 11 & 22.0 \\
\hline $2.2-2.4$ & 9 & 18.0 \\
\hline $2.5-2.7$ & 4 & 8.0 \\
\hline $2.8-3.1$ & 4 & 8.0 \\
\hline Total Table 3. Energy Setting \\
\hline \multicolumn{3}{|c|}{} \\
\hline \multicolumn{2}{|c|}{} \\
\hline
\end{tabular}

Most of the capsulotomies were done at the level of energy between $1.6 \mathrm{~mJ}$ to $2.4 \mathrm{~mJ}$ as shown in Table 3. It consisted of 32 eyes. 10 capsulotomies were done at the level of $1.2 \mathrm{~mJ}$ to $1.5 \mathrm{~mJ}$, while 8 capsulotomies were done at the level of $2.5 \mathrm{~mJ}$ to $3.1 \mathrm{~mJ}$. The minimum amount of energy used was $1.2 \mathrm{~mJ}$ and maximum amount of energy used was $3.1 \mathrm{~mJ}$.

In our case series, thirty-nine patients required total energy between $30 \mathrm{~mJ}$ and $90 \mathrm{~mJ}$. Out of them, thirty-one required below $60 \mathrm{~mJ}$, A total of 2 patients required more than $90 \mathrm{~mJ}$, and 1 patient required more than $120 \mathrm{~mJ}$. The maximum amount of energy used was $124 \mathrm{~mJ}$ and minimum was $14.4 \mathrm{~mJ}$.

In our case series, preoperatively 38 patients had best corrected visual acuity of counting fingers to $6 / 24$. Only 2 patients had BCVA of appreciating only hand movements and another 2 patients had BCVA of $6 / 12$ and 8 patients had BCVA of 6/18.

Postoperatively, 36 patients had BCVA of 6/9 and 6/6. 5 patients had BCVA $6 / 12$ and seven patients had BCVA of $6 / 18$. Only one patient had BCVA $\leq 6 / 36$, he developed cystoid macular oedema and with treatment his vision improved.

\begin{tabular}{|c|c|c|}
\hline Improvement & No. of Patients & Percentage \\
\hline$>3$ lines & 25 & 50.0 \\
\hline$>2$ lines & 18 & 36.0 \\
\hline$>1$ line & 7 & 14.0 \\
\hline No improvement & 0 & 0 \\
\hline Decrease & 0 & 0 \\
\hline Total & $\mathbf{5 0}$ & $\mathbf{1 0 0}$ \\
\hline \multicolumn{2}{|r|}{$\begin{array}{r}\text { Table 4. Distribution of Improvement } \\
\text { of Vision in Snellen's Chart }\end{array}$} \\
\hline
\end{tabular}

Improvement of 3 lines or more was seen in 25 patients, 18 patients had an improvement of 2 lines and 7 patients had an improvement of 1 line.

\begin{tabular}{|c|c|c|}
\hline IOP & No. of Patients & Percentage \\
\hline$<14 \mathrm{mmHg}$ & 9 & 18.0 \\
\hline $14-15.9 \mathrm{mmHg}$ & 21 & 42.0 \\
\hline $16-17.9 \mathrm{mmHg}$ & 12 & 24.0 \\
\hline $18-19.9 \mathrm{mmHg}$ & 6 & 12.0 \\
\hline $20-21.9 \mathrm{mmHg}$ & 2 & 4.0 \\
\hline$>22 \mathrm{mmHg}$ & 0 & 0 \\
\hline Total & 50 & 100.0 \\
\hline
\end{tabular}

In our case series, thirty-three patients were in the range of $14 \mathrm{mmHg}$ to $18 \mathrm{mmHg}$, and 6 were above $18 \mathrm{mmHg}$. 9 patients had IOP less than $14 \mathrm{mmHg}$ preoperatively as shown in table 5. The minimum IOP found in the group was 10.2 $\mathrm{mmHg}$ and maximum of $20.6 \mathrm{mmHg}$.

Distribution of postoperative intraocular pressure at 4 hours: 34 patients were in the range of $14-18 \mathrm{mmHg}$ and 8 patients had intraocular pressure between $18 \mathrm{mmHg}$ and $20 \mathrm{mmHg}$.

In our case series, thirty-four patients had intraocular pressure between 14-18 mmHg, 7 patients had pressure less than $14 \mathrm{mmHg}, 7$ patients had intraocular pressure between $18-20 \mathrm{mmHg}, 2$ patients had intraocular pressure greater than $20 \mathrm{mmHg}$ after 4 hours of YAG Laser.

The patients were followed up for a period of 6 months. Out of 50 patients treated, 2 patients had acute rise of intraocular pressure. Both the patients were treated with antiglaucoma medications, their pressures returned to base line.

IOL pitting was observed in 4 patients. This pitting was not visually significant and did not produce any glare or image degradation.

3 patients developed iritis, which was treated with topical steroids and cycloplegics. Iritis resolved subsequently without causing any significant longterm reduction of vision.

1 patient developed $\mathrm{CME}$, with treatment it resolved without any deteriorating effect on vision.

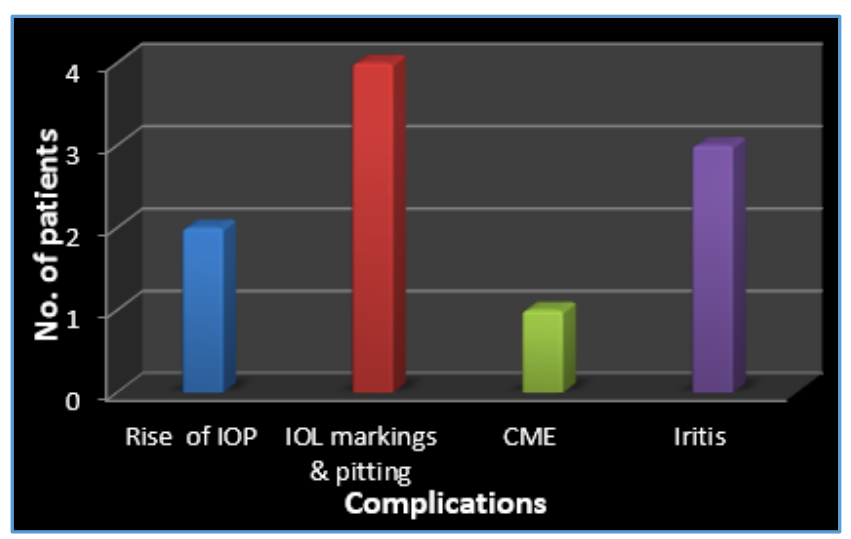

Figure 2. Distribution of Complications

\section{DISCUSSION}

The occurrence of complication is due to size of PCO opening and the total energy level delivered. The common causes for raised IOP was deposition of debris in trabeculum, pupillary block and inflammation of iris and ciliary body with angle closure. ${ }^{13}$ Keates et al found iritis in $0.4 \%$ and vitritis in $0.7 \%$ after a 6-month postoperative period. Anterior chamber flare is seen post laser treatment. ${ }^{13}$ Hassan et al found $19.8 \%$ IOL pitting in a case series. The retrofocusing of laser beam will reduce the IOL damage. ${ }^{13}$ Hussain MM reported CME in $0.8 \%$ in eyes treated with $\mathrm{Nd}$ : YAG laser. ${ }^{16}$ YAG laser produces vitreous liquefaction. ${ }^{16}$ Levy et al reports displaced IOL after laser treatment.13 Pupillary block glaucoma, macular hole, retinal haemorrhage, low grade endophthalmitis.

This procedure has its own merits and demerits. It is noninvasive but can carry the list of some complications. ${ }^{13}$ The time period between cataract extraction and performing $\mathrm{Nd}$ : YAG laser capsulotomy was 2.49 years by Hasan et al and 24 months by Kundi and Younas. The predominant type of PCO was capsular fibrosis which differs from Hasan et al who reported Elschnig's pearls to be the predominant type in pseudophakic eyes. 
Hasan et al noted that improvement of visual acuity after Nd: YAG laser capsulotomy on Snellen's chart was 1-3 lines in 42 and 4-6 lines in 31 out of 86 patients. A similar case series showed improvement of visual acuity, more Snellen's lines in 56 out of 63 eyes. Latif and Aasi using Nd: YAG laser showed overall $87.5 \%$ improvement in the visual acuity of an average 3 lines on Snellen's chart. Nd: YAG laser use has been accepted as a standard technique for treating PCO resulting in rapid visual improvement.

Straylight is correlated with the severity of the PCO and that corrected distance visual acuity (CDVA) and straylight values improved significantly after $\mathrm{Nd}$ : YAG laser capsulotomy. ${ }^{17}$ Straylight is a sensitive, additional indicator for capsulotomy referral, especially in less severe cases of PC0.18 Nd: YAG laser posterior capsulotomy did not significantly change anterior chamber depth and spherical equivalent. 19

The acrylic hydrophobic IOL showed better results when related to the incidence and intensity of one piece acrylic hydrophilic IOL. ${ }^{20}$

In patients who underwent, phaco surgery and combined vitrectomy, Nd: YAG capsulotomy was found to be safe and effective. ${ }^{21}$

\section{CONCLUSION}

The case series of Nd: YAG laser in the treatment of posterior capsular opacification after cataract surgery conducted on 50 eyes in the Department of Ophthalmology, RMMCH, Chidambaram concludes that the improvement in visual acuity is excellent after Nd: YAG laser capsulotomy. It is relatively non-invasive and can be performed as an OPD procedure.

Since PCO is a visually disabling condition reducing ability of patient to carry out the activities of daily living, Nd: YAG laser capsulotomy with its remarkable outcome on visual acuity and with least complications acts as a boon to such patients limiting the need for undergoing a second operative procedure. It thereby reduces the cost that could have been imposed by operating room usage and inpatient care.

Although this procedure is safe, it is associated with complications like transient intraocular pressure rise, pitting of the intraocular lenses, mild iritis which are not vision threatening and they are transient. Therefore, this treatment modality is cost effective and safe.

\section{REFERENCES}

[1] Bari KN. Nd: YAG laser posterior capsulotomy and visual outcome. Delta Med Col J 2013;1(1):16-9.

[2] Gore VS. The study of complications of ND: YAG laser capsulotomy. Int J Bioinformatics Res 2012;4(2): 265-8.

[3] Pandey SK, Apple DJ, Werner L, et al. Posterior capsule opacification: a review of the aetiopathogenesis, experimental and clinical studies and factors for prevention. Indian J Ophthalmol 2004;52(2):99-112.

[4] Boureau C, Lafuma A, Jeanbat V, et al. Cost of cataract surgery after implantation of three intraocular lenses. Clin Ophthalmol 2009;3:277-85.

[5] Alipour F, Jabbarvand M, Khodaparast M, et al. Hinged capsulotomy-does it decrease floaters after Yttrium aluminum garnet laser capsulotomy? Middle East Afr J Ophthalmol 2015;22(3):352-5.
[6] Ram J, Brar GS. Posterior capsule opacification: an overview. DOS Times 2006;12(4):285-9.

[7] Vock L, Menapace R, Stifter E, et al. PCO and Nd: YAG laser capsulotomy rates with a round-edged silicone and a sharp-edged hydrophobic acrylic intraocular lens 10 years after surgery. J Cataract Refract Surg 2009;35(3):459-65.

[8] Georgopoulos M, Findl O, Menapace R, et al. Influence of intraocular lens material on regeneratory posterior capsule opacification after Nd: YAG laser capsulotomy. J Cataract Refract Surg 2003;29(8):1560-5.

[9] Bai L, Zhang J, Ma T, et al. Comparison of posterior capsule opacification at 360-degree square edge hydrophilic and sharp edge hydrophobic acrylic intraocular lens in diabetic patients. Int J Ophthalmol 2015;8(4):725-9.

[10] Bhargava R, Kumar P, Prakash A, et al. Estimation of mean Nd: Yag laser capsulotomy energy levels for membranous and fibrous posterior capsular opacification. Nepal J Ophthalmol 2012;4(1):108-13.

[11] Bhargava R, Kumar P, Phogat H, et al. Nd: YAG laser capsulotomy energy levels for posterior capsule opacification. J Ophthalmic Vis Res 2015;10(1):37-42.

[12] Hawlina G, Olup BD. Nd: YAG laser capsulotomy for treating posterior capsule opacification. J Laser Health Academy 2013;1:S34-5.

[13] Karahan E, Duygu ER, Kaynak S. An overview of Nd: YAG laser capsulotomy. Med Hypothesis Discov Innov Ophthalmol 2014;3(2):45-50.

[14] Francis A, L'Esperence. Ophthalmic lasers: photocoagulation, photoradiation and surgery. $2^{\text {nd }}$ edn. Mosby 1983:79-83.

[15] Katzen LE, Fleischman JA, Trokel SL. The YAG laser: an American experience. J Am Intraocular Implant Soc 1983;9(2):151-6.

[16] Khanzada MA, Jatoi SM, Narsani AK, et al. Is the $\mathrm{Nd}$ : YAG laser a safe procedure for posterior capsulotomy. Pak J Ophthalmol 2008;24(2):73-8.

[17] Yotsukura E, Torii H, Saiki M, et al. Effect of Nd: YAG laser capsulotomy on visual function in patients with posterior capsule opacification and good visual acuity. J Cataract Refract Surg 2016;42(3):399-404.

[18] Van Bree MC, van den Berg TJ, Zijlmans BL, et al. Posterior capsule opacification severity, assessed with straylight measurement, as main indicator of early visual function deterioration. Ophthalmology 2013;120(1):20-33.

[19] Khambhiphant B, Liumsirijarern C, Saehout P. The effect of Nd: YAG laser treatment of posterior capsule opacification on anterior chamber depth and refraction in pseudophakic eyes. Clin Ophthalmol 2015;9:557-61.

[20] Schriefl SM, Menapace R, Stifter E, et al. Posterior capsule opacification and Nd; YAG laser capsulotomy rates with 2 microincision intraocular lenses: fouryear results. J Cataract Refract Surg 2015;41(5):95663.

[21] Georgalas I, Petrou P, Kalantzis G, et al. Nd: YAG capsulotomy for posterior capsule opacification after combined clear corneal phacoemulsification and vitrectomy. Ther Clin Risk Manag 2009;5(1):133-7. 